\title{
Dos nuevos epitafios hebreos de la necrópolis del Castro de los Judíos (Puente del Castro, León)
}

\author{
Javier CASTAÑO \\ Universidad Complutense, Madrid \\ José Luis AVELlo \\ Universidad de León \\ (Con la colaboración de Margarita TAscón)
}

\section{Los judíos de Puente del Castro}

Un año después de su destrucción en 1196, Alfonso IX donaba a la catedral y al obispo de León «... iure hereditario castrum iudeorum cum sua uilla, situm super ripam de Torio iuxta Legionem et omnes uinneas et omnes terras tam cultas quam incultas ad iudeos pertinentes» ${ }^{1}$. Meses antes se había puesto fin de manera violenta al importante asentamiento judío ligado a la corte regia leonesa.

Sobre la orilla del río Torío y cerca de León se levanta aún el cerro de la Mota o la Mota del Castro donde se advierten una serie de alteraciones del terreno que solamente se pueden explicar a partir de la actuación humana, con restos arqueológicos esparcidos por una amplia extensión de terreno. Este espacio arqueológico engloba varias unidades de población que se suceden tanto en el marco temporal como en el geográfico. Ya desde el período medieval hay conciencia de la antigüedad del poblamiento y han ido apareciendo restos materiales durante las labores agrícolas ${ }^{2}$.

* Los autores agradecen la imprescindible colaboración de D. Porfirio García de Arriba desde aquel primer y extraño encuentro un 19 de octubre de 2000 . El estudio arqueológico ha corrido a cargo de José Luis Avello y la traducción y estudio del texto hebreo son de Javier Castaño.

1 Archivo de la Catedral de León, núm. 1073 (13 jul. 1197), en Julio GoNZÁLEZ GONZÁlEZ, Alfonso IX (Madrid 1944) tomo II núm. 105 págs. 153-155.

2 Ya en el siglo XIII Fray Juan Gil de Zamora recoge una tradición que hace referencia al topónimo Sublantia, cercano a León, y que podría identificarse con el nombre que se utilizaba para denominar un manantial ferruginoso localizado 
Se constata en el yacimiento la presencia de materiales arqueológicos de diversas épocas, desde la II Edad del Hierro (siglos XI-I a.E.c.) hasta comienzos del siglo XIII, cuando se atestigua su destrucción ${ }^{3}$. El estado actual sólo revela el aspecto general del último poblamiento al que se deben sumar las distintas alteraciones producidas por las actividades agrícolas practicadas en el cerro, las obras de apertura y nuevos trazados de caminos, la instalación de un depósito de agua cuyo edificio aún se conserva aunque nunca llegó a funcionar y las actividades erosivas.

El conjunto arqueológico se compone de una plataforma, cuyo perímetro asemeja un ocho, rodeada de una barrera artificial en forma de talud y que comprende una superficie de unas 5 hectáreas. Hacia el norte se eleva una pequeño recinto de unos 3.000 metros cuadrados. Es probable que esta pequeña ciudadela sea artificial y que hubiera sido elevada con los materiales extraídos del impresionante foso que fue excavado para defender el poblado en su zona norte que originalmente era la más accesible. Es este recinto el que estaría habitado. Hacia el oeste el Torío discurre bajo los escarpes sedimentarios del cerro, asegurándole protección y proporcionándole agua suficiente para abastecer a la población y a las industrias que debieron estar asentadas a su orilla. Por el este el arroyo del Barranco crea una barrera natural entre el Castro y los campos circundantes. A mediodía, la ladera se extiende en abanico hacia Puente del Castro. En la zona más baja es donde se han encontrado las estelas funerarias, ya que alberga la necró-

hasta hace poco en las inmediaciones de Puente del Castro: la Fuente Sublantina. Fray Juan Gil de Zamora en su De preconiis Hispaniae (ed. Manuel CASTRO Y CASTRO [Madrid 1955] pág. 214) dice: «... Legio fuit Flos primitus appellata ... Traianus namque imperator, natione Hispanus, contra Occidentem per Romanum Imperium destinavit quatordecim militum legiones ... Ex quibus, due venerunt in Hispaniam et civitates Sublantiam et Florem destruentes, non longe ab ipsa Flore, urbem condiderunt, quam Legio vocaverunt ...». El nombre Fuente Sublantina pudo haberse originado con posterioridad.

${ }^{3}$ El Tudense señala en su Chronicon Mundi que Alfonso IX de León ordenó destruir varios castillos en 1212, después de haber ordenado la demolición del Castro por la amenaza que representaban para la capital: «... Tunc rex Adefonsus destruxit Gordonem, et Arbolium, ut legionensis civitas securitate frueretur et pace. Iam olim destruxerat iudaeorum castrum juxta Legionem, quia eadem civitati multa damna saepius inferebat ...» (Lucas de Tuy, Crónica de España, ed. Julio PUYOL [Madrid 1926] pág. 416). 
polis judía, cuyo extremo meridional está hoy bajo parte del casco urbano del actual Puente del Castro ${ }^{4}$.

La disposición del cerro permite diferenciar un castillo en la parte más elevada que sería construido durante la Alta Edad Media sobre un castro anterior ${ }^{5}$. La disposición de los elementos conservados -foso, colina artificial que sobresale por encima del territorio circundante- y la toponimia -Cerro de La Mota o La Mota del Castro- certifican un tipo de fortificación típica y característica de la Alta Edad Media de todo el occidente medieval y que se empleará en el norte peninsular en épocas muy tempranas: la mota ${ }^{6}$. Debieron estar parcialmente habitados el territorio rodeado por el talud, la zona más alta de la ladera meridional y también al este el espacio comprendido entre el talud y el arroyo del Barranco, que en la actualidad recibe el nombre de El Castro.

Los primeros análisis sistemáticos de este yacimiento arqueológico y de sus vicisitudes históricas aparecen recogidos en un importante estudio que fue presentado por José María Luengo al VI Congreso Nacional de Arqueología de 1959. En él el autor estudia el que denomina Castro de la Candamia, aportando una serie de datos muy significativos para conocer su secuencia evolutiva.

Basándose en el estudio de los restos arqueológicos conservados en la colección privada de Sánchez Cañón y en el análisis in situ, Luengo planteaba una secuencia de tres momentos culturales. El primero de ellos, correspondiente a la II Edad del Hierro, estaría representado por una fíbula de arco y varios fragmentos de cerámica pintada de filiación celtibérica. Gracias a ello se comprueba que hacia occidente el fenómeno celtibérico llegó hasta las puertas de lo que luego sería el embrión de la actual ciudad de León. La segunda fase estaría avalada por la presencia de tégulas, baldosas

\footnotetext{
${ }^{4}$ Información descriptiva adicional sobre el Castrum Iudaeorum en José Avelino GUTIÉRREZ GONZÁLEZ, Fortificaciones y feudalismo en el origen y formación del reino leonés (siglos IX-XIII) (Valladolid 1995) págs. 249-250.

5 Antes de la aparición del término Castrum Iudaeorum aparece en la documentación del siglo X el término Castrum Rege. La fundación estaría ligada a las necesidades defensivas de la ciudad de León y al mantenimiento de los intereses regios en el cruce del puente del Castro por donde pasaba el camino de Santiago (GUTIÉRREZ GONZÁLEZ Fortificaciones pág. 250).

6 Luis De MORA-FIgUeroA, Glosario de arquitectura defensiva medieval (Cádiz 1996) s.v. mota, págs. 140-141.
} 


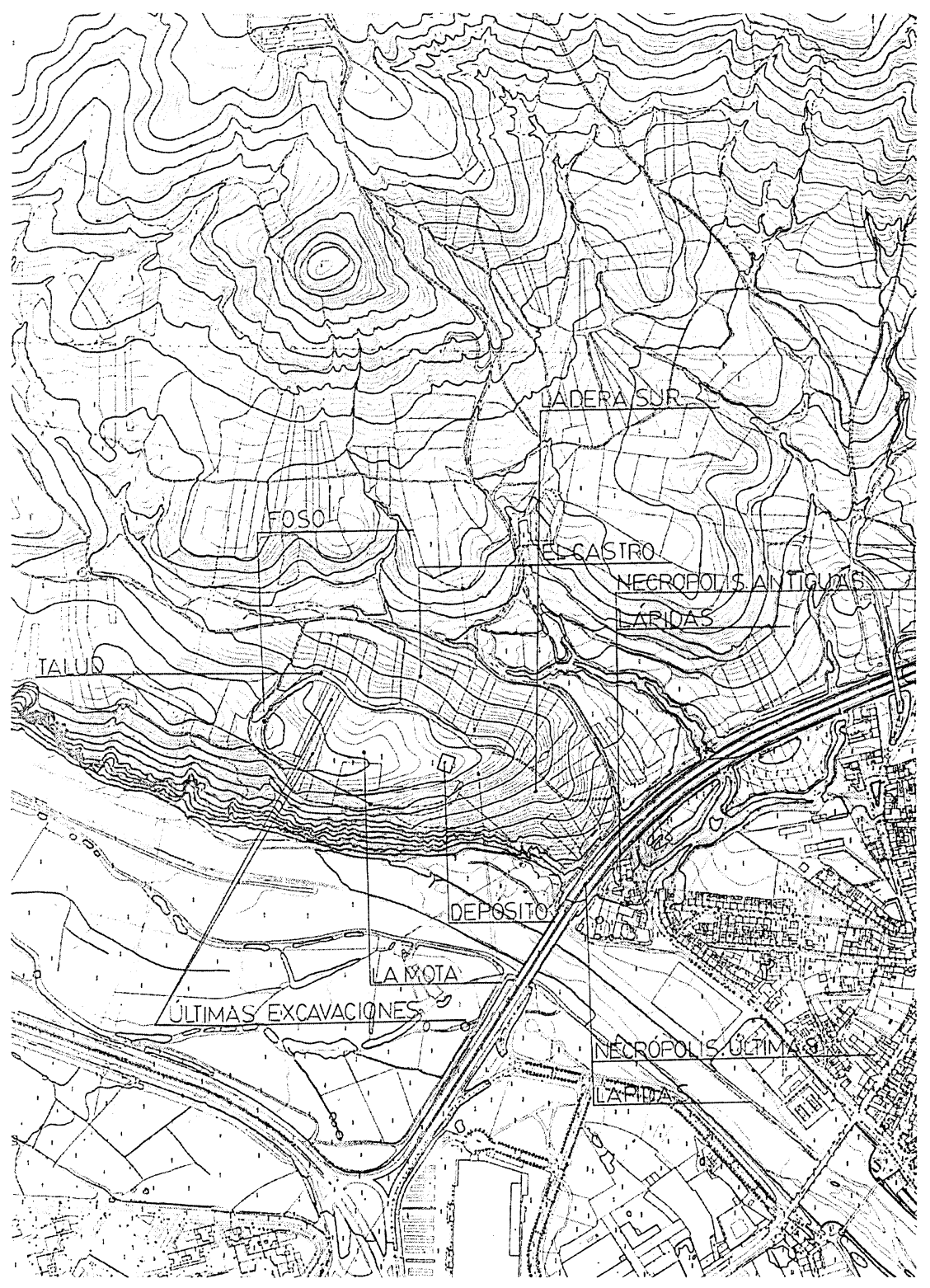

Plano topográfico del Castro de los Judíos (elaborado por José Luis Avello) 
y ladrillos. Por último, señala un tercer momento medieval, bien documentado a partir de la documentación escrita ${ }^{7}$.

De gran interés es la información que señala la existencia «de tres grupos de cuevas, cavadas unas sobre otras en el terreno, en todo similares a las de Lancia, Villacontilde, Valle de Mansilla, Rueda de Almirante ...» ${ }^{8}$. En la actualidad este grupo de cuevas está oculto por los desplomes que se producen a causa de la erosión provocada por las escorrentías de las aguas. En Puente del Castro aún se conserva el recuerdo de la llamada Cueva del Moro.

La población del Castrum Iudaeorum alcanzó cierta relevancia durante los siglos XI y XII. No cabe duda de que era un conjunto urbano que por sus dimensiones pudo haber alcanzado una notable cantidad de habitantes para la época ${ }^{9}$. Es una población complementaria de la de la ciudad de León, y aunque alejada de la propia capital del reino, jugó un importante papel estratégico en el plano defensivo: el camino jacobeo y el puente del Castro serían dos elementos decisivos en el auge de la población.

El yacimiento arqueológico guarda en sus entrañas el urbanismo típico de una pequeña ciudad de la meseta septentrional correspondiente a los siglos XI y XII. Pocos despoblados altomedievales gozan de esta particularidad pues la mayoría están bajo los

7 José María Luengo Martínez, «Castros leoneses: Revilla, Sacaojos, Ardón, La Candamia, Villafañe y Valderas», reimpreso en sus Estudios arqueológicos (Astorga 1990) págs. 97-133: esp. págs. 106-109. Las prospecciones de superficie emprendidas en diversos momentos por los directores de las excavaciones que actualmente se llevan a cabo (José Luis Avello y Jorge Sánchez-Lafuente) no han constatado la presencia de los elementos celtibéricos. Más que un error de clasificación por parte de Luengo, cuyos estudios acerca de la presencia de la cultura celtibérica en la provincia de León son aún válidos, habría que cuestionar la misma formación de la colección de Sánchez Cañón.

8 LUENGO MARTínEZ «Castros leoneses» pág. 106. Estas cuevas deben de estar relacionadas con un fenómeno eremítico de más amplio alcance y situado en las proximidades de León. En la margen izquierda del río Torío existía, además de la cueva de San Martín de Villademoros, la Peña Cavada dedicada a San Miguel y otra llamada de San Torcuato, próxima a la de San Martín. En 1006 el monje Gonzalo, hijo de Zauen, vivía en una ermita en la peña sobre el río Torío la cual había sido propiedad de Maniulfo. Vid. José Luis Avello Álvarez y María Dolores CAMPOS SÁNCHEZ-BORDONA, «La ermita rupestre de Villademoros de las Regueras», Diario de León (14 jun. 1992) pág. 11.

9 En ningún momento hay que pensar que todos sus habitantes fueran judíos. Más bien se trataría de un núcleo judío levantado al amparo de la fortificación, a la cual se añadirían otros grupos de pobladores. 
cimientos de otros más modernos. Su destrucción a fines del siglo XII y sobre todo su abandono como centro de población garantizan el sellado de su evolución urbanística. El Castrum Iudaeorum de León es fiel reflejo de una forma de poblamiento típica de otras localidades y que aún no ha sido estudiada. Como en ellas, el término parece aludir «al barrio judío, tantas veces cobijado al amparo de la posición fortificada de una villa» ${ }^{10}$, como ocurre en Astorga o en Mayorga.

La proximidad a la capital del reino debió servir de reclamo a numerosos grupos de población. Los judíos se asentaron en sus inmediaciones porque, al igual que el castillo, eran también propiedad del rey. Allí los nuevos pobladores pudieron desarrollar múltiples actividades, algunas de ellas constatadas por las fuentes escritas, como el trabajo de la piel o la alfarería ${ }^{11}$.

Del refinamiento intelectual de esta comunidad, acorde a su situación en la cabeza del reino, dan prueba diversos testimonios, alguno de ellos tardío, como el transmitido por Abraham Zacut en relación a la posesión de un códice de la Biblia hebrea, el Codex Hil lelí, reflejo de su interés por asuntos masoréticos, códice que tras la destrucción del Castro en 1196 sería trasladado a Castilla ${ }^{12}$.

La destrucción de este enclave está relacionada con el enfrentamiento entre castellanos y leoneses, y la actitud mantenida por estos últimos en torno al desastre castellano en Alarcos en 1195, y aparece bien testimoniada tanto en fuentes narrativas hebreas como castellanas y leonesas ${ }^{13}$. Unidades militares conjuntas caste-

10 Cfr. Francisco Cantera Burgos, «Juderías medievales de la provincia de León», Archivos Leoneses 55-56 (1974) págs. 85-155: pág. 138.

11 Cfr. José Avelino GutiérRez GonZÁlEZ y Carmen BenEITEZ GonZÁlez, «La cerámica medieval en León», en La cerámica medieval en el Norte y Noroeste de la Península Ibérica (León 1989) págs. 213-214, donde se incluye un importante lote cerámico del siglo XII procedente de Puente del Castro, cuyas muestras aunque recogidas superficialmente presentan cierta uniformidad, que «por las condiciones de agrupación en zonas reducidas, piezas defectuosas y la homogeneidad del conjunto nos hace pensar razonablemente en la existencia de un taller de producción cerámica, a pesar de que no hayan aparecido aún estructuras ni elementos de alfar».

12 Abraham Zacut, Séfer Yuhasín ha-Šalem, ed. Hirshell FILIPOwSKI (London Edinburgh 1857) pág. 220b.

13 Ecos de la destrucción del Castro aparecen en las crónicas del Tudense y del Toledano, en la Crónica latina de los reyes de Castilla y en las narraciones históricas hebreas de Yosef ben Șadic de Arévalo y Abraham ben Šelomó. 
llano-aragonesas habían atacado la capital del reino y ante la imposibilidad de tomarla destruyeron el Castro tras un asedio que comenzó el 23 de julio de 1196 y finaliza dos días después con la captura de la fortaleza y el incendio de la judería y de la sinagoga. El sábado 27 de julio todos los moradores eran llevados en cautiverio ${ }^{14}$. La destrucción tuvo que ser completa, ya que no volvemos a tener noticias documentales acerca de los judíos del Castro y su cementerio quedaría abandonado.

\section{HAllazgos en la NeCRÓPOlis del CASTRo de los Judíos}

Hay que esperar hasta 1847 en que se produce el primer hallazgo conocido y relacionado con la población judía de Puente del Castro, al encontrarse casualmente una lápida funeraria que sería poco después publicada por Amador de los Ríos ${ }^{15}$. En 1902 se publica una interesante síntesis histórica sobre la localidad de Puente del Castro. En ella, su autor, que realiza una recuperación de algunos restos materiales, señala sin plantearse duda alguna que en la Mota y el Castro es donde se asentaron los judíos aunque «... fue castro de los romanos, antes de que los hebreos lo dedicasen a castillo propio». Ramón Álvarez de la Braña definió este yacimiento como romano a partir de los restos recuperados - «fragmentos de teja, una estatuita de bronce, varias bolitas de piedra, fibulas y otros objetos de fábrica romana, algunos de los cuales poseemos»-, y comprueba que sobre «la elevada planicie» el «terreno está compuesto en gran parte del ditritus de las ruinas y sembrado de fragmentos de tejas romanas y restos de vasijas y ladrillos de igual procedencia» ${ }^{16}$.

14 La narración más detallada es la que aparece recogida (hacia 1468) por Yosef ben Saḍic de Arévalo en el capítulo 50 de su Quișur Zéjer ŝadic; cf. Yolanda MORENO KOCH, Dos crónicas hispanohebreas del siglo XV (Barcelona 1992) pág. 47 (según el texto hebreo editado por Adolf Neubauer, Medieval Jewish Chronicles [Oxford 1887] tomo I pág. 94, que lo toma del manuscrito oxoniense). El texto hebreo diferencia un barrio judío dentro del Castro, que sería incendiado tras la captura de la fortaleza. De su lectura no se infiere que todo el Castro fuera

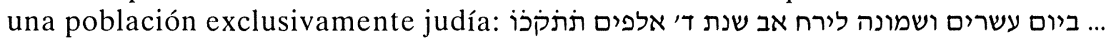
לחדוש העולם נלכד מבצר קאשטרו מליאון ונשרפה העיר של היהודים.

15 José AMADOR DE LOS RIOS, Historia social, politica y religiosa de los judíos de España y Portugal (Madrid 1875) vol. I pág. 170.

16 Ramón Álvarez de la Braña, Apuntes para la Historia del Puente del Castro (León 1902) págs. 10-11. Es difícil valorar el conocimiento que el autor poseía acerca de la cultura material hispano-romana. Según las prospecciones 


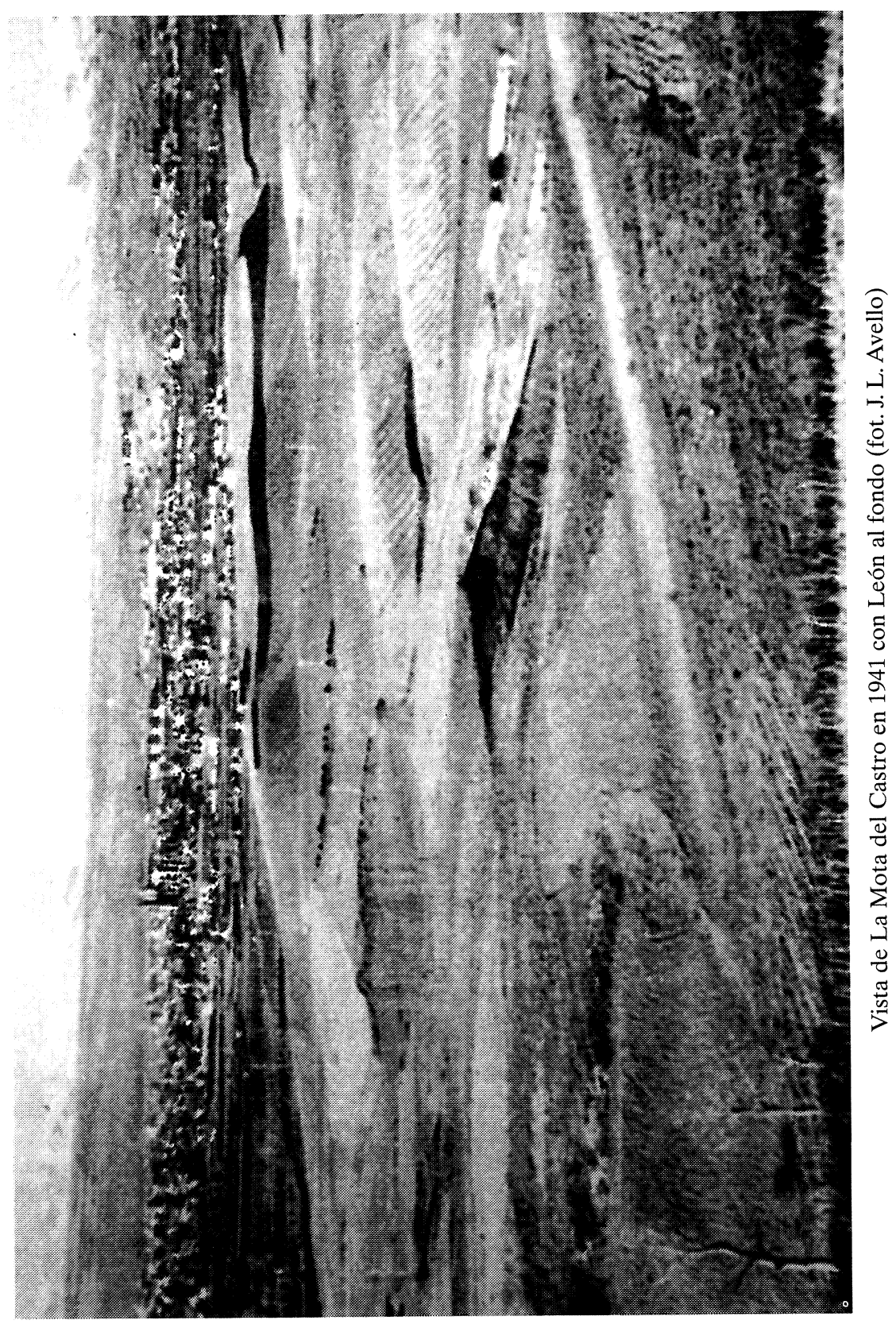


Dos años después, en 1904, se vuelven a encontrar dos nuevas lápidas que fueron compradas por Eloy Díaz Jiménez-Molleda y dadas a conocer por Fidel Fita ${ }^{17}$. Al poco tiempo, en 1906, apareció un nuevo epígrafe funerario que fue adquirido también por Eloy Díaz ${ }^{18}$. El mismo año, cuando Manuel Gómez Moreno visita la ciudad de León con el fin de elaborar el catálogo monumental de la provincia, registra en el Museo Arqueológico la existencia de cinco lápidas hebreas procedentes del cementerio del Castro ${ }^{19}$. Este autor remitiéndose a lo escrito por Álvarez de la Braña alude al Cerro de la Mota como Castro de los Judíos:

porque realmente fue población de ellos, como acreditan varios epitafios hebreos de los siglos XI y XII allí descubiertos, y dos de ellos grabados sobre plintos de basas romanas ... Además, de que fue población romana se evidencia con restos de cerca de mampostería vistos en el cerro, fragmentos de tégulas y vasijas y algún ladrillo con marca ${ }^{20}$.

Hasta 1942 no se da a conocer otro nuevo hallazgo de epígrafes en Puente del Castro. Aparece entonces una importante pieza que

realizadas en los últimos años por parte del equipo que actualmente lleva a cabo las excavaciones arqueológicas en la Mota del Castro no se han hallado tales evidencias. Todos los restos superficiales ofrecen una clara tipología medieval. Tres fragmentos de terra sigillata se encontraron en las catas realizadas en 1999. La presencia de tejas planas romanas se advierten en las inmediaciones del cruce del camino nuevo a Golpejar con el que asciende hacia el depósito de agua en dirección a la Mota, pero se trata de un escombro vertido no hace muchos años. Álvarez de la Braña también encontró fuera de este recinto y «a corta distancia de la Nevera, pequeño edificio destinado a depósito de hielo, entre varios pedazos de teja plana, dos fragmentos de ladrillo refractario, restos, sin duda, de algún hornillo de fábrica romana, pues conservaban trazos en hueco de los caracteres de una leyenda latina» (Apuntes pág. 12). Es posible que estos materiales se puedan adscribir a fechas relacionadas con el mundo romano pues la presencia de tejas planas no se documenta, actualmente, sobre la superficie de la Mota del Castro.

17 Fidel FITA, «Dos lápidas sepulcrales hebreas de la Candamia conservadas en el Museo Arqueológico de León», Boletín de la Real Academia de la Historia [= BRAH] 47 (1905) págs. 137-147.

18 Fidel FITA, «Nueva inscripción hebrea de León», BRAH 50 (1907) págs. 33-36.

19 Manuel Gómez Moreno, Catálogo Monumental de España: Provincia de León (1906-1908) (Madrid 1925) pág. 172. Paradójicamente, ninguna de ellas está hoy en León: tres permanecen depositadas en el Museo Sefardí de Toledo y dos continúan en paradero desconocido.

20 Gómez Moreno Catálogo pág. 7. 
ofrece una inscripción en el anverso y otra en el reverso ${ }^{21}$, la cual se expone actualmente en el Museo Diocesano en el claustro de la catedral de León por cesión del entonces archivero capitular Raimundo Rodríguez Vega. En 1954 Francisco Cantera publica un nuevo epitafio que apareció fragmentado e incompleto a corta distancia del anterior ${ }^{22}$.

A raíz de ello, se llevó a cabo la primera prospección arqueológica en la necrópolis judía, financiada por la Comisaría General de Excavaciones a propuesta del Instituto Arias Montano del CSIC, en la que se descubren varias sepulturas; sus resultados, infructuosos en el terreno epigráfico, nunca se llegaron a publicar. Dos años después, en 1956, aparece la primera visión de conjunto de las inscripciones funerarias hebreas del Castro dentro del corpus epigráfico hispano-hebreo publicado por Cantera y Millás ${ }^{23}$ que registra noticias sobre ocho inscripciones, de las cuales sólo seis habían podido ser localizadas.

De nuevo en 1963 se descubre fortuitamente una nueva inscripción que pasa a formar parte de la colección del Museo Diocesano de León ${ }^{24}$. Va a ser en el mismo lugar del hallazgo en donde se harán unas excavaciones arqueológicas en el año 1973, que pondrán al descubierto cuatro sepulturas judías con orientación oesteeste sin ajuar, además de una inscripción fragmentaria junto a una de ellas. Los resultados de la excavación quedan detalladamente expuestos en los años siguientes ${ }^{25}$.

21 Francisco CANTERA BuRgos, «Nuevas inscripciones hebraicas leonesas», Sefarad 3 (1943) págs. 329-358.

22 Francisco CANTERA Burgos, «Nuevo hallazgo epigráfico en León», Sefarad 14 (1954) págs. 119-121.

23 Francisco Cantera Burgos y José María Millás Vallicrosa, Las inscripciones hebraicas de España (Madrid 1956) págs. 5-24.

${ }^{24}$ Estudiada en Francisco CANTERA BuRgos, «Un epitafio hebraico más descubierto en Puente del Castro», Sefarad 24 (1964) págs. 3-11.

25 Enrique Pérez Herrero y Federico Pérez CASTro, «Puente Castro: Excavación de cuatro tumbas medievales judías y hallazgo de un nuevo epitafio hebreo», Sefarad 34 (1974) págs. 30-41. Puede verse una descripción de los resultados de la excavación en Enrique PÉREZ HERRERO, «La necrópolis hispano-hebrea de Puente Castro (León)», Studium Legionense 17 (1976) págs. 177-190; y una síntesis de los estudios sobre necrópolis judías medievales peninsulares en los estudios de Enrique PÉREZ HERRERO, «Apuntes para el estudio de las necrópolis judías de época medieval o ensayo de tipología sepulcral», Sefarad 38 (1978) págs. 333-355, y de Jorge CASANOVAS MIRÓ, «Notas sobre arqueología funeraria judía en época medieval», Espacio, Tiempo y Forma 6 (1993) págs. 293-302. 
En paralelo con los hallazgos epigráficos se producen avances sustanciales en el conocimiento documental de las juderías medievales de León y su provincia gracias a las pioneras investigaciones de Justiniano Rodríguez Fernández ${ }^{26}$, y sobre todo, a la publicación del detallado estudio de Francisco Cantera Burgos, que sigue manteniendo su rigor histórico pese a los años transcurridos ${ }^{27}$.

\section{EXCAVACIONES RECIENTES EN LA NECRÓPOLIS}

En junio de 1983 a causa de las obras de la variante de circunvalación en la nueva carretera León-Valladolid se produce la destrucción de la necrópolis judía situada en Puente del Castro, pese a la denuncia presentada por Justiniano Rodríguez Fernández a la Delegación Territorial del Ministerio de Cultura.

Durante julio y agosto de ese año el entonces director de excavaciones de urgencia de León, José Luis Avello Álvarez, realiza una prospección en un pequeño sector que aún quedaba sin destruir. Al afectar a la parte más baja de la pendiente, la nueva carretera dividía en dos el cementerio judío, dejando una parte de la necrópolis junto a las casas de Puente del Castro y la otra al lado opuesto de la carretera. Estas excavaciones pusieron al descubierto varios enterramientos que ocupaban una parte de la ladera que desde la Mota desciende en dirección a la antigua alcoholera de Puente del Castro. Se trata de una zona de terreno arcilloso que había sido arrastrado desde la parte superior de la Mota, y cuya potencia superaba en todos los puntos los $140 \mathrm{~cm}$. Por ello el material hallado en el terreno correspondía a cerámica muy fragmentada que procedía de las zonas más altas.

La memoria de la excavación detalla las labores que pusieron al descubierto dos niveles de enterramientos:

El sector a excavar se marcó con tres calles que cubrieran la mayor parte afectada, subdivididas en cuadros de $4 \times 4 \mathrm{~m}$. con pasillos de $1 \mathrm{~m}$. En conjunto se pudieron diferenciar dos niveles

26 Justiniano Rodríguez FernÁndez, La judería de la ciudad de León (León 1969) (cf. la precisa reseña crítica de esta obra publicada por F. CANTERA en Sefarad 30 [1970] págs. 60-66). Basándose en sus estudios anteriores este mismo autor publica más tarde su obra Las juderías en la provincia de León (León 1976).

27 Nos referimos a su artículo «Juderías medievales» que Cantera había publicado dos años antes. 
de enterramientos: el nivel I apareció a $-1,50$ m.; responde a un grupo de enterramientos infantiles practicados en fosa simple excavada en la arcilla (ya de sedimentación por arrastre) y un sólo caso en el que se había realizado una sepultura de lajas, piedras sin desbastar, de tamaño medio, y entre ellas un molino de mano circular, flanqueando y cubriendo la inhumación. El estado de los restos óseos era pésimo, debido a la falta de protección y fragilidad de los mismos, correspondientes a individuos de muy corta edad. El nivel II, bajo una capa de sedimentos arcillosos arrastrados de zonas superiores, aparece a 2,10 m. y corresponde a inhumaciones de adultos en fosas acondicionadas y endurecidas con «caleño» y abiertas en niveles arcillosos. La forma de las fosas tiende al trapecio y al tipo «bañera», ligeramente más ancho en la cabecera, que se presenta orientada hacia el este. La posición más general observada es decúbito supino con los antebrazos cruzados sobre la pelvis. La alineación de las fosas crea «pasillos» entre ellas, observándose una organización previa a la utilización de las mismas. Carecían, como las infantiles del nivel I, de todo tipo de ajuar; en el interior de la fosa tan sólo han aparecido improntas y restos de madera, clavos y anillas, pertenecientes al ataúd, en algunos enterramientos. En los rellenos de algunas otras fosas aparecieron cuentas de collar, de cobre, y objetos de piedra y hueso; la cerámica, escasa en este nivel, está muy fragmentada, y no puede suponerse colocada intencionalmente, debido a formar parte de esa sedimentación o relleno posterior ... El nivel II corresponde a una época de mortandad «normal», en la que se podían organizar y planificar las fosas con cierta precisión, mientras que el nivel I, de enterramientos infantiles, además de ser muy posterior, como lo demuestran los sedimentos que lo separan del inferior, demuestra apresuramiento y poco cuidado en la ejecución de la inhumación, correspondiente quiza a una fuerte mortandad (infantil, a juzgar por los hallazgos de este sector), que podría responder a los últimos momentos de ocupación del lugar ${ }^{28}$.

\section{Dos NUEVOS HALlAZGoS EPIGRÁFICOS}

Simultáneamente a las obras de la carretera se encontraron en 1983 dos nuevas inscripciones funerarias, que estudiamos a continuación.

28 Los resultados de la excavación de urgencia fueron dados a conocer en José Luis Avello Álvarez y José Avelino GuTiÉrRez GonZÁlez, «Excavaciones en la necrópolis de la judería del Castro (Puente Castro, León)», Boletín de Información de Arqueología Medieval 1 (s.a. [= 1986]) pág. 13. 


\subsection{Epitafio de ¿1092?}

Javier Alaiz hizo el primer hallazgo al pie de la ladera de ascenso a la Mota y en las proximidades del río Torío. La pieza había sido desplazada a ese lugar por el empuje de las máquinas de la obra y por tanto es difícil precisar su localización original. La lápida se realizó probablemente aprovechando un antiguo molino de mano abarquillado ${ }^{29}$. Se conserva únicamente la parte inferior que comprende las tres últimas líneas; falta el nombre del difunto y para su datación, que queda incompleta, podría señalarse el año [ ¿48?]52, es decir, 1091-1092. El material es cuarzo con elevado contenido de arenisca y las dimensiones actuales 350/297 mm. de anchura, $175 \mathrm{~mm}$. de altura y $210 \mathrm{~mm}$. de grosor. Hay que destacar el esmerado trazado de las letras (15-16 mm. altura), pendientes de líneas horizontales trazadas con punzón. He aquí el texto hebreo:

$$
\begin{aligned}
& \text { [...] מאות וחמש[ים ו]ש[תים] הקלהה } 30
\end{aligned}
$$

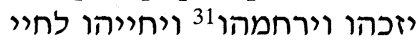

$$
\begin{aligned}
& \text { העולם הבא אמן }
\end{aligned}
$$

[...] cientos cincuenta y dos ${ }^{32}$, el Santo bendito sea

le dé merito y tenga misericordia de él y lo reviva a la vida de el mundo venidero. Amén.

\subsection{Epitafio de 1097}

Tampoco es posible proporcionar datos precisos sobre la localización original de la segunda lápida, descubierta también de manera fortuita mientras se removía tierra durante los trabajos previos a la construcción del desdoblamiento de la carretera en 1982, aunque la noticia pública del descubrimiento se produce en octubre de 2000 .

\footnotetext{
${ }^{29}$ Puede verse la noticia de su descubrimiento y descripción en José Luis AVELLO ÁlVAREZ, «Inscripción hebraica procedente de la necrópolis de la judería del Castro (Puente Castro, León)», Boletín de Información de Arqueología Medieval 3 (1987 [mayo 1988]) pág. 13. La pieza fue donada por D. Javier Alaiz al Museo de León en 1983 (núm. 5680, 83-5-1).

30 Los puntos superpuestos señalan la abreviación de la eulogia הקדוש ברוך הוא ha-cadóš baruj hú en הקבה hcbh.

31 La expresión aparece recogida en otras inscripciones leonesas, particularmente la \# 4 del repertorio de CANTERA - MILLÁs Inscripciones pág. 14.

32 Podría corresponder a los años [48]52 (=1091-1092) y [49]52 (=1191-1192), aunque un análisis detallado del trazado de la escritura, similar a otras lápidas leonesas del mismo período, nos inclina a aceptar la primera fecha.
} 


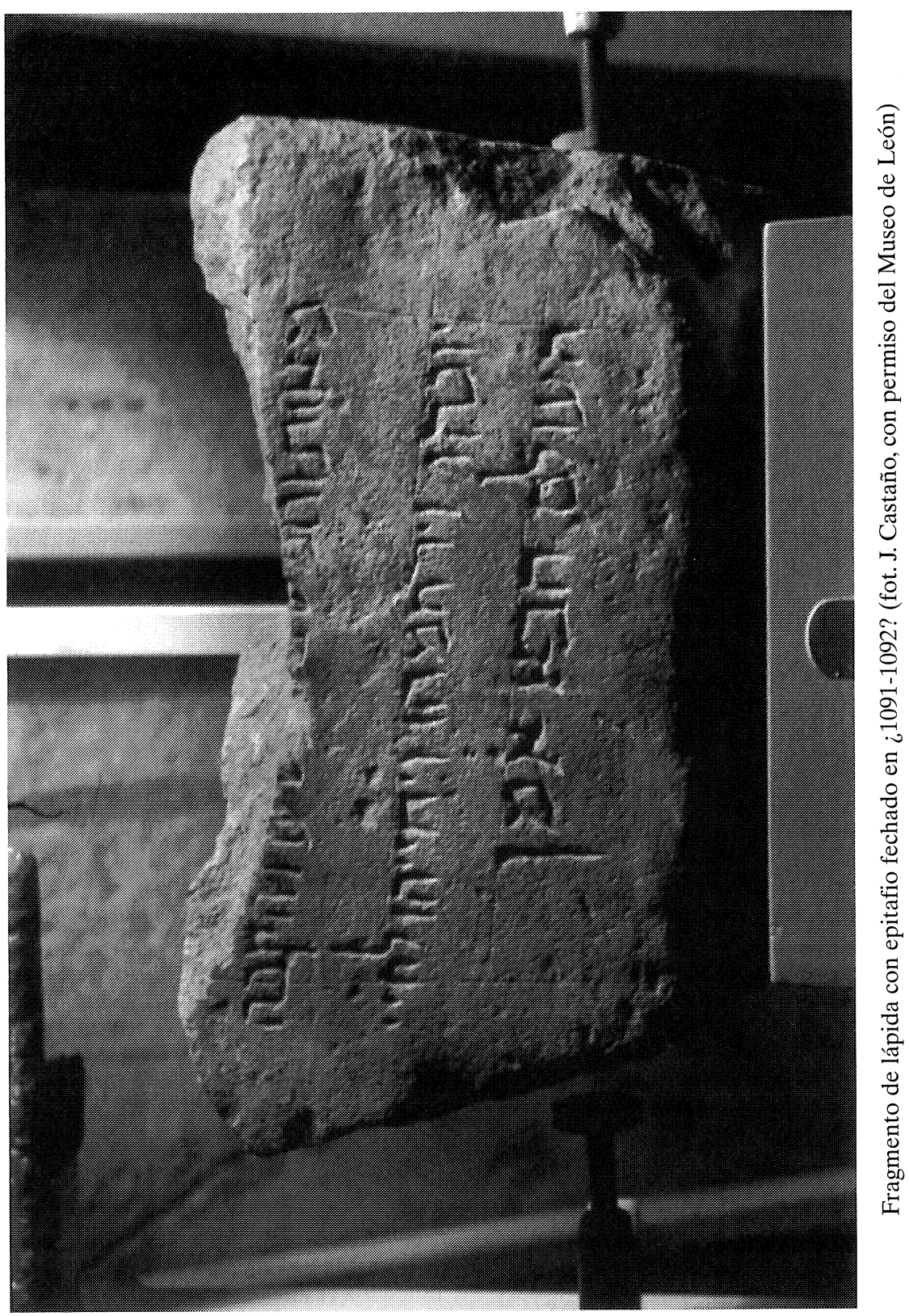


La inscripción es en este caso de mayor interés que la primera. Nos encontramos, sin duda, ante el mejor de los epitafios leoneses conocidos por la amplitud del texto y por su magnífico estado de conservación ${ }^{33}$.

Se trata de una pieza rectangular de estructura trapezoidal, lisa en la cara de la inscripción, que comprende 16 líneas de texto. Una de sus peculiaridades es la preservación de abundantes restos de coloración roja en el interior de las letras de las cuatro líneas inferiores del texto. Este es un dato que habrá que tener en cuenta a partir de ahora, ya que parece ser el primer caso registrado en las lápidas peninsulares ${ }^{34}$.

Sus dimensiones son $380 \mathrm{~mm}$. de altura, 297/304 mm. de anchura y $40 / 65 \mathrm{~mm}$. de grosor. Al igual que en la lápida anterior, la primera letra tiene una altura de $14 \mathrm{~mm}$. Su escritura es la cuadrada, con algunos caracteres trazados en cursiva, pendiente de líneas horizontales. Aunque de trazado elegante y uniforme presenta algún titubeo en su diseño.

El texto menciona a Šelomó bar David ben Parnaj, fallecido a la edad de cuarenta años, el miércoles día 3 de ab de 4857, que corresponde al 15 de julio de 1097. El texto hebreo es el siguiente:

$$
\begin{aligned}
& \text { זה הקבר למי35 שלמה בר }
\end{aligned}
$$

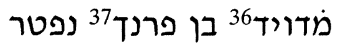

$$
\begin{aligned}
& 3 \\
& \text { שלושה ימים לירח אב שנת שנת בנים } \\
& \text { ארבעת אלפים } \\
& 6 \text { וחמשים ושבעה לבריאת ומשת משת }
\end{aligned}
$$

${ }^{33}$ El 21 de octubre de 2000 la lápida se depositó finalmente en el Museo de León (núm. 200026), gracias a la generosa entrega realizada al Museo en nombre de la familia García de Arriba.

${ }^{34}$ Se trata, sin embargo, de una práctica documentada en el norte y este de Francia en tiempos más recientes, como puede verse en el repertorio de Gérard NAHON, Inscriptions hébraïques et juives de France médiévale (Paris 1986) passim.

${ }_{35}$ Abreviatura de mar, tratamiento honorífico no determinado en esas época y región que quizá pueda traducirse por 'don, señor'.

${ }^{36}$ En el trazado de la 7 final se produce cierto titubeo en la mano del epigrafista, que puede hacer confundir ese carácter con una ๆ.

37 Aunque parece poder leerse פרנד, la lectura sugerida aquí coincide con Parnaj, padre de Elișafán, príncipe de Zebulún, mencionado en Núm 34:25.

${ }^{38}$ Las letras $\mathrm{x}$ y $ל$ aparecen unidas formando un solo carácter. 


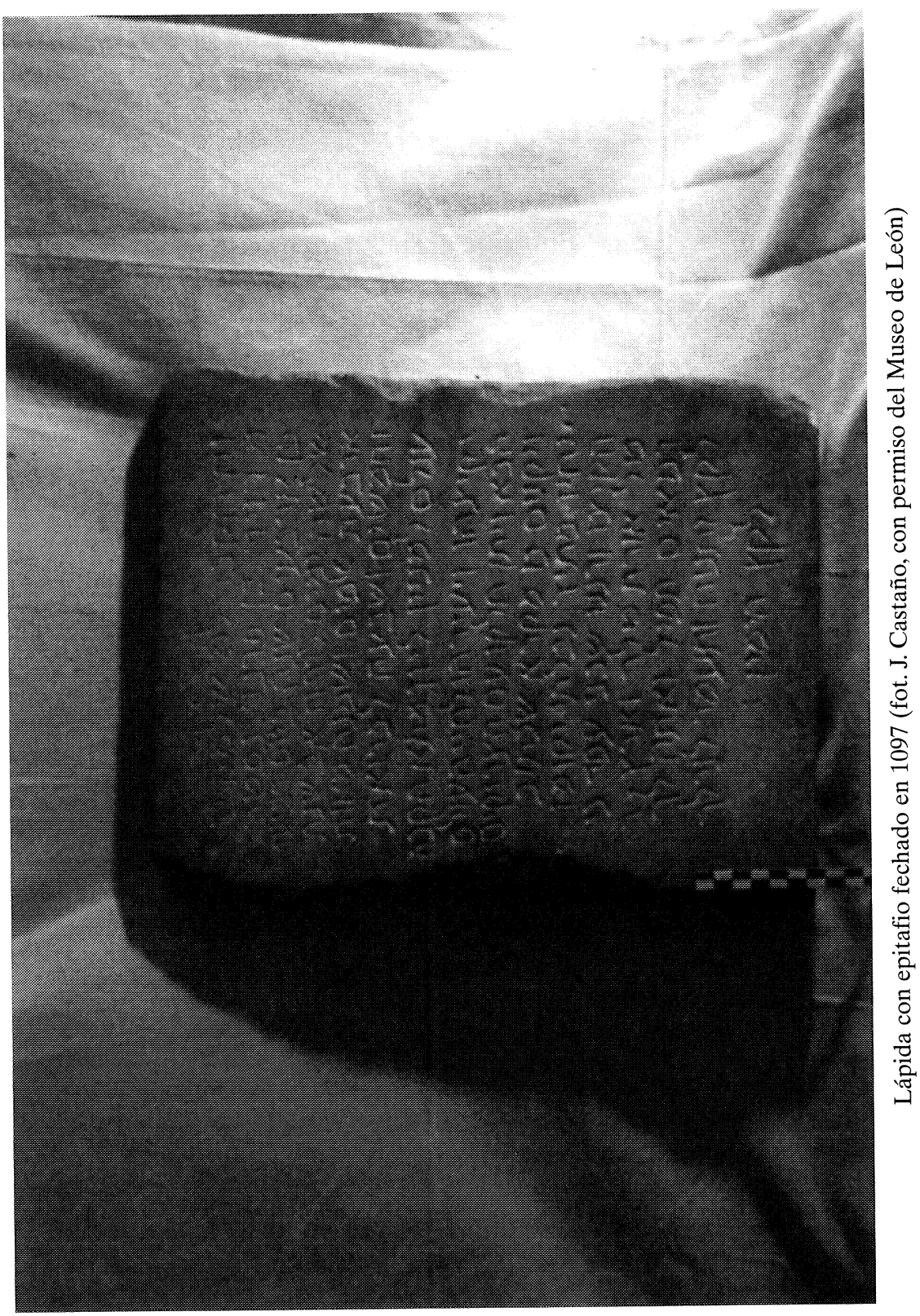




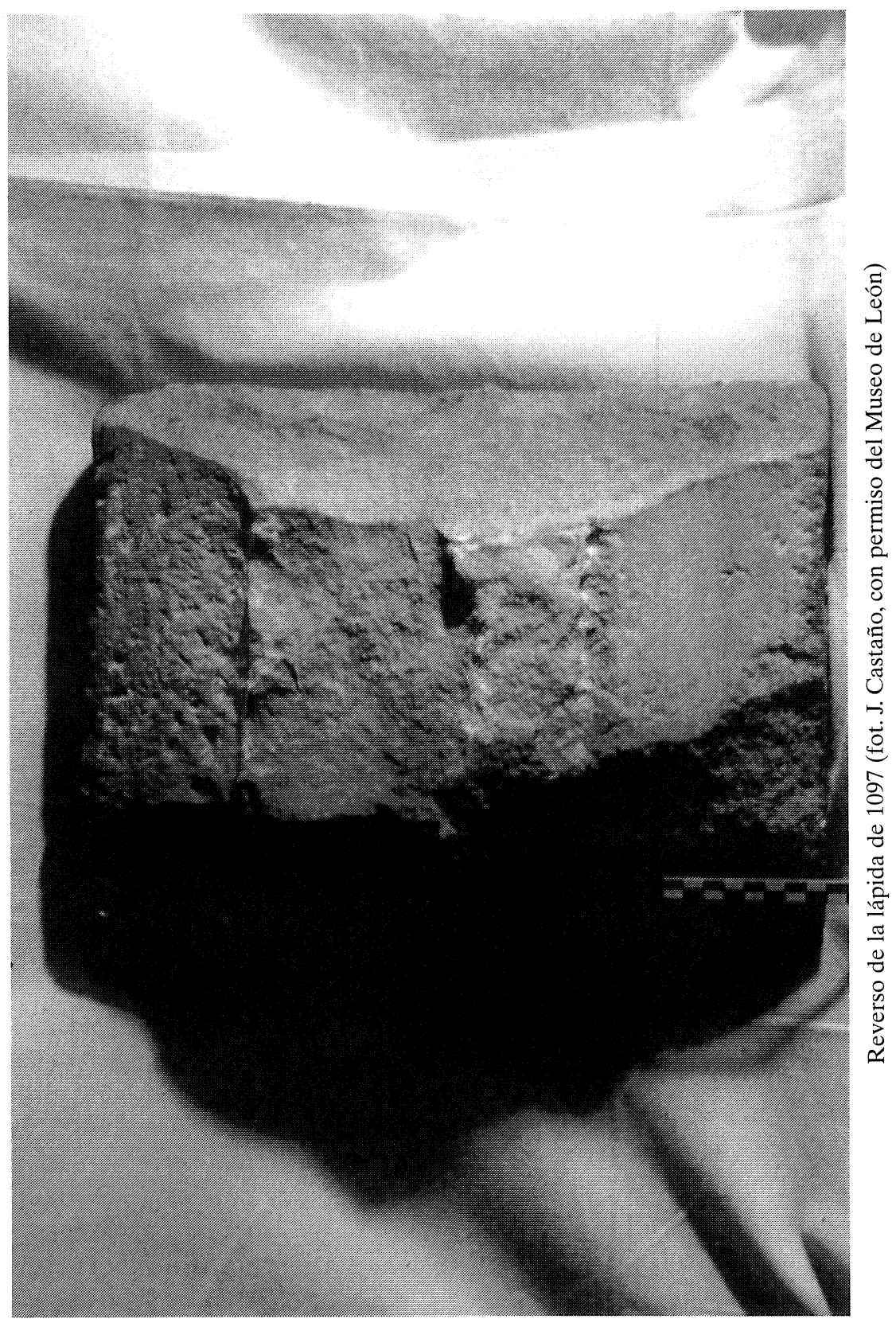




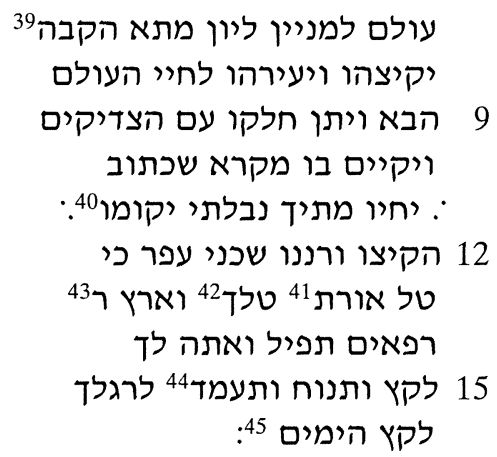

Esta es la sepultura de mar Šelomó bar mar David ben Parnaj fallecido

3 a la edad de cuarenta años el miércoles día 3 del mes de ab, año cuatro mil ochocientos

6 cincuenta y siete de la Creación del mundo según el cómputo de la ciudad de León ${ }^{46}$, el Santo bendito sea

le levante y le despierte a la vida del mundo

9 venidero y le otorgue su parte con los justos y cumpla en él el pasaje bíblico donde está escrito Revivirán tus muertos, mis cadáveres se levantarán

12 despertad y exultad, los que yacen en el polvo, pues rocío de luz es tu rocío y la tierra muertos parirá ${ }^{47}$, mas tú ve

39 Aquí la abreviatura הקבה no lleva puntos superpuestos.

${ }^{40}$ Con escritura defectiva; en el texto masorético [= TM] es יקומון.

41 TM: אורות.

42 Las dos 0 de la línea 13 tienen un trazado cursivo; contrástese con la $v$ de línea 2.

43 Primera letra de la palabra רפאים, que ante la excesiva longitud de esta línea se escribe entera en la siguiente; ello sucede en otras inscripciones leonesas.

44 TM: תעמוד.

45 TM: היממון.

${ }^{46} \mathrm{O}$ sea, el de la era de la Creación, utilizado tanto en los documentos hebreos leoneses, como en otras piezas epigráficas del lugar.

47 Is 26:19; este mismo versículo aparece también en CANTERA - MILlás \# 5 (1102/4862) y en la lápida estudiada por CANTERA BURGOS «Un epitafio hebraico más». A la luz de las interpretaciones rabínicas hay que entender el texto como 
15 al fin y descansa y te levantarás para tu suerte al fin de los días ${ }^{48}$.

A partir de la documentación escrita leonesa no es posible añadir más datos acerca del individuo del cual conservamos su lápida funeraria. El tratamiento honorífico de mar es de uso común en las restantes piezas epigráficas leonesas. Sí conviene señalar otras dos singularidades de la lápida, cuya explicación no hemos encontrado. Enmarcando la línea 11 del texto aparecen al comienzo y al final dos puntos con inclinación descendente diagonal hacia la linea de escritura. Y en la parte inferior derecha del reverso de la lápida figura grabada una $\checkmark$, con inclinación de 45 grados hacia la derecha y de menor tamaño que los caracteres trazados en la cara anterior de la lápida.

Para concluir digamos una vez más que no cabe duda de que estamos ante la mejor pieza epigráfica leonesa descubierta hasta el momento de las doce catalogadas. Si bien las obras de 1982-1983 desenterraron las dos piezas estudiadas arriba, sin embargo y pese a los esfuerzos de los arqueólogos, supusieron la destrucción de parte de la necrópolis judía leonesa (que parece haber sido utilizada hasta 1196), al ser removidos los terrenos y quedar sumergida bajo el asfalto de la carretera.

Pero aún no se ha dicho la última palabra. Dada la importancia del yacimiento arqueológico en su conjunto, acorde con la centralidad del asentamiento en el antiguo reino leonés, la Junta de

sigue: «Los hijos de Israel, que son tuyos, aunque ahora parecen muertos, revivirán, y también los que ya han muerto se levantarán de sus tumbas. Vosotros, los muertos que yacéis en el polvo, despertáos y exultad; pues como rocío de la mañana (o rocío revivificador de la hierba, $o$ rocío de vida) así es tu rocío; y la tierra, igual que hace brotar las plantas en ella escondidas, así dejará escapar a los muertos de sus entrañas» (cf. por ejemplo M. D. CASSUTO, Sifré ha-Micrá: Isaías, ed. A. S. HARTOM [10 ed.: Tel-Aviv 1960] págs. 91-92). El pasaje se recita a la entrada del cementerio y luego en el servicio fúnebre o השכבה haškabá.

48 Dan 12:13; el versículo aparece en otras inscripciones funerarias, como por ejemplo CANTERA - Millás \# 49 y 84 (Toledo), \# 123, 130 y 134 (Barcelona), \# 166, 169 y 190 (Gerona), y \# 192 (Castellón de Ampurias). Según la interpretación rabínica, así debemos entender el pasaje: «Ve y vive hasta que te llegue el final de tus días y entonces descansarás en tu tumba hasta que llegue la resurrección de los muertos en que te levantarás para recibir la suerte que te corresponda» (cf. CAssuto Sifré ha-Micrá: Daniel, ed. HARTOM [6ª ed.: Tel Aviv 1960] pág. 63). El texto se recita en las הקפות למת hacafot la-met, en el estribillo que acompaña desde la cuarta a la séptima estrofa. 
Castilla y León otorgó en 1999 un permiso de excavación a José Luis Avello Álvarez y a Jorge Sánchez-Lafuente Pérez para realizar excavaciones en el Castro de los Judíos, labores que se vienen realizando desde ese mismo año en campañas anuales, con la colaboración del consistorio leonés, que ha proporcionado ayuda económica, además de adquirir las fincas en donde se realizan los trabajos.

Las excavaciones se han proyectado al menos en cinco campañas, de las cuales se han ultimado ya las de 1999 y 2000 centradas de momento en la prospección de la parte superior de la Mota, dentro del recinto fortificado. Esperamos que dichas excavaciones ya en marcha arrojarán una nueva luz acerca de las actividades desarrolladas en el recinto fortificado del Castro durante los siglos XI y XII.

\section{SUMARIO}

En anteriores números de Sefarad se ha venido dando puntual noticia de descubrimientos epigráficos funerarios relativos a la necrópolis judía del Castro de los Judios en Puente del Castro (León), asentamiento judío de la capital del reino de León en el momento de su mayor esplendor (siglos XI-XII), y que fue destruido y abandonado en 1196. Se da noticia aquí de las excavaciones de urgencia realizadas en 1983 en la necrópolis judía altomedieval antes de ser arrasada durante la construcción de una nueva carretera de circunvalación, además del importante y fortuito hallazgo de dos nuevas inscripciones de fines del siglo XI, una de ellas fragmentaria y la otra en excelente estado de conservación, que son estudiadas con detalle. Además, se da cuenta de las excavaciones en la Mota del Castro iniciadas en 1999.

\section{SUMMARY}

Previous issues of this journal, having published news about epigraphic findings regarding the Jewish graveyard of the Castro de los Judios in Puente del Castro (León), have underscored the importance of this community, derived from having been the Jewish settlement at the capital city of the Leonese kingdom (in the $11^{\text {th }}$ and $12^{\text {th }} \mathrm{c}$., before it was destroyed by a foreign army in 1196). Recent archaeological excavations were undertaken in 1983, before the graveyard disappeared, razed, under a new highway that was built upon it. Simultaneously, two new important epigraphic pieces of the late $11^{\text {th }} \mathrm{c}$., analysed here with detail, have been found, if haphazardly. Additionally, details are given of the new archaeological excavations started in 1999 at the Castro's Mota. 